\title{
The scholarship of teaching and learning from a social justice perspective
}

Brenda Leibowitz and Vivienne Bozalek

\begin{abstract}
We argue that there is a reciprocal relationship between all scholarly activities, most importantly between teaching, learning, research and professional learning. The article builds on the work of others who call for a social justice approach to inform the SoTL. It focuses on the implications for professional learning, as an aspect of the SoTL which has been neglected. The tripartite account of participatory parity as advanced by Nancy Fraser is shown to be a valuable frame to describe instances of social justice, as well as the kind of institutional arrangements that should be instituted to support participatory parity. Alongside this, the notion of a 'pedagogy of discomfort' is shown to be an effective, but challenging means to advance awareness of justice and injustice amongst academics. The article draws on examples from three action based research projects run by the authors.
\end{abstract}

\section{Introduction}

In this article we wish to contribute to debates on the scholarship of teaching and learning (SoTL) by placing the concept within a social justice framework, most specifically that informed by the work of Nancy Fraser on participatory parity. We pose what we see as a relational or reciprocal view: that whatever aspects of teaching and learning one is dealing with and that one may be researching - whether the facilitation methods, the choice of research design, the graduate attributes enshrined in policy and programme documents, or the nature of the support for academics to engage in the SoTL - these should all be discussed in relation to the same social justice principles.

We begin this article with comments on the origins and definitions of SoTL before outlining the social and educational setting which has given rise to the approach towards the SOTL that we have taken. We then move to outline key concepts we are working with in relation to social justice, based on the views on social justice and participatory parity advanced by Nancy Fraser. We sketch in broad terms the implications of these principles for practice. After outlining the research design of the three research projects we refer to, in the penultimate section we illustrate how the principle of reciprocity plays itself out in professional development work with examples from our experience in this field, and finally, we summarise the implications for the professional development of academics. 


\section{TheSoTL}

The SoTL is an endeavour intersecting with various fields relating to the enhancement of higher education teaching and learning. It received its initial definition by Ernest Boyer (1990). Boyer's initial impetus was to advocate for integration of the work of an academic, and not for the autonomous status for the SoTL. He stressed the interrelationship between theory and practice: 'The arrow of causality can, and frequently does, point in both direc- tions. Theory surely leads to practice, but practice also leads to theory. And teaching, at its best, shapes both research and practice' (Boyer 1990, 15/16). He placed emphasis on the scholarliness inherent in good teaching, thus on the notion of reciprocity between all matters of scholarship that we have been arguing for in the introduction to this article:

good teaching means that faculty, as scholars, are also learners. ... Through reading, through classroom discussion, and surely through comments and discussions and questions posed by students, professors themselves will be pushed in creative new directions. (Boyer 1990, 24)

The field of SoTL is distinguished from other forms of higher educational development in that it involves a degree of reflection, research or scholarship which is usually achieved in the process of academics researching their own teaching and learning contexts. In many cases, it also includes students as researchers of their own learning and as knowledge producers (Griffiths 2004). A definition that embodies SoTL is 'where academics frame questions that they systematically investigate in relation to their teaching and their students' learning' (Brew 2007, 1/2). Although there are a variety of conceptions of the SoTL, the idea that it is about academics and students engaged in research on their own teaching and learning is the view adopted for the purposes of this article.

Hutchings (2000) maintains that what distinguishes SoTL from other educational research is that it is conducted by specialists and non-specialists alike. Thus, despite the fact that not all teaching-based research refers to itself as 'SoTL', the SoTL banner remains a useful focus for theorising the research on teaching and learning (RTL) conducted by academics and the support for this work, and is for this reason the focus of this article. The increasing popularity of the SoTL and the manner in which it has been taken up has led to an emphasis on the value of SoTL to encourage academics' professional learning (Hutchings, Huber, and Ciccone 2011). Thus, there is a high stake attributed to the kind of research that is undertaken in the name of SoTL. Does this research live up to its potential? Kreber (2013b) argues that it does not, partly because of how narrowly it tends to be understood, within an 'evidence-led' instrumentalist paradigm, and that it 'has not adequately taken up the bigger questions of social justice and equality in and through higher education' (2013a, 5). We acknowledge that the field of SoTL includes a wide variety of pedagogical approaches (Hutchings, Huber, and Ciccone 2011). A significant view on the SoTL is that it ought to have a critical and transformative or social justice orientation (Gale 2009; Gilpin and Liston 2009; Kreber 2013a). Our position is that the social justice aspect of SoTL has received inadequate attention, and this is the lacuna that we wish to contribute to. 


\section{Research and teaching context}

We have both worked in higher education in South Africa for the past four decades, thus during and post-apartheid. We have witnessed the oppression and injustice of the apartheid era and its continuing effects. The present dispensation has indeed contained forms of transformation in society and education, but overall there has been a disappointing lag in the movement towards change and equity (Cooper 2015; Department of Education 2008). Thus, whilst there have been significant changes and evidence of transformation in higher education, as we have argued elsewhere (Leibowitz and Bozalek 2014) there remain major disparities with regard to: the provisioning in higher education as well as with regard to the social, educational and cultural capital of students entering and exiting the system. There has been a publically expressed disappointment in the ability of universities to transform their institutional ethos into a more welcoming one (Tabensky and Matthews 2015) and one that not only turns its head in deference to and in imitation of dominant Western culture (Badat 2009). With regard to the teaching cohort in higher education, the most senior levels are predominantly white, middle class, and male, especially in the more historically advantaged institutions (HAIs), whereas the historically disadvantaged institutions (HDIs) have a large contingent of black teachers (see Cooper 2015 for more details on this). Inequality in the country has always tended to coalesce along lines of race and class, but in the present period class has tended to become slightly more salient, with more privileged students identifying themselves in terms of both race and class (Cooper 2015; Soudien 2008). Students and academics bring into the teaching and learning space vestiges of memories of oppression and oppressive thinking typical of the apartheid era. Jansen (2009) refers to this collective and enduring memory as 'knowledge in the blood' and Costandius (2012) describes how years of indoctrination would have influenced her thinking as a white Afrikaans speaking academic. Writings in the edited volume by Tabensky and Matthews (2015) suggest that many students or academics still do not feel 'at home' in higher education institutions in South Africa, and educational social mobility amongst academics remains a problem (Mabokela 2000). In short, social injustice persists with regard to matters of ethnicity and identity, thus of recognition, matters of distribution of material and cultural resources, and matters of power and voice, thus of framing (Bozalek and Boughey 2012). We will return to this tripartite account of social justice in the next section, with a discussion of the work of Nancy Fraser and participatory parity - suffice it to say that student and staff participation at university is impeded by social injustice in relation to these three dimensions.

With the democratic dispensation post-1994 and the opening up of South African society, increasing numbers of students and academics from the rest of Africa have entered the country. Despite official policies of welcome, this opening up has been met with outbreaks of xenophobia, in 2008 and 2015 (see Aljazeera 2015; Human Rights Watch 2008). These have admittedly affected people living in working class and rural areas rather than some of the more privileged spaces such as universities. This phenomenon serves to demonstrate that as change occurs, so other challenges appear, such as xenophobia. The point is simply that there is always a reason why teaching is challenged to respond to societal phenomena, and to be based on a sound ethical foundation and vision. 


\section{Social justice and teaching and learning}

We see SoTL and social justice as interrelated. Moje (2007) makes the distinction in relation to general education between socially just pedagogy (equitable learning conditions for academic success) and a pedagogy for social justice (transformation of learners, knowledges and contexts through critical questioning and engagement). ${ }^{1}$ Kreber (2013a) makes the same claim for a form of SoTL that she claims is 'authentic', in and through higher education. She sees authenticity as involving transformative learning, and as implicating both students and all academics in a process of becoming. Kreber argues that teachers achieve this authenticity through reflection: about the purpose of education, about student learning and development; and about knowledges, curricula and pedagogy. We extend this relational ontology even further, where the spheres affected by the need for reflection and reflexivity go so far as to include: the kind of research that is adopted by academics, and the principles for professional development and learning of the academics themselves. As an example of how we see academics as part of the same learning cycle as students, we found in the past that expecting students to undergo learning and unlearning processes, especially ones that are uncomfortable - what drawing from Boler and Zembylas (2003) we referred to as a 'pedagogy of discomfort - requires academics and those conducting change initiatives and researching these, to have similar learning experiences (Leibowitz et al. 2010).

This notion of reciprocity can be further extended, to inform the advocacy that academics engage in: how we agitate for better conditions for ourselves and students, so that teaching for social justice and in a socially just manner can be realised. Hutchings, Huber, and Ciccone $(2011,6)$ write that academics who work actively to enhance learning work 'against the grain' and that preparation and collaboration necessary to support educational innovation often goes against 'the inherited routines of academic life'. This has implications for academic developers, who should advocate for enhanced conditions for the SoTL in universities (Brew and Jewell 2012). In a compelling account of how opting for a teachingfocused position can marginalise an academic, Ragoonaden (2015) demonstrates how the high value of research outputs versus teaching is part of a larger hegemonic discourse of performativity. She maintains that university educators 'should be advocating for practices that benefit society as well as emergent transformative scholarly cultures in academia to build just, inclusive, democratic communities' (2015, 10/11). This points to a role for those who support the research of others, which Apple $(2013,43)$ describes in relation to educationists more generally as 'tense' and embodying 'dual commitments': to be role models and credible scholars, as well as to be activists and focusing on change in and through higher education.

\section{Dimensions of social justice: participatory parity}

In this section we advocate that social justice pedagogy be underpinned by the writing of political philosopher Nancy Fraser. Although Nancy Fraser is not a critical theorist in pedagogy, her work has been used by critical pedagogy, particularly in relation to her notion of participatory parity, which she equates with social justice (see for example 
Apple, Au, and Gandin 2009). The three dimensions of social justice as advanced by Nancy Fraser $(2008,2009)$ are a useful frame for exploring the implications of a socially just pedagogy. These dimensions are the economic, the cultural and the political, each of which either mitigates against or contributes to social justice. Fraser $(2008,2009)$ equates social justice with the ability to interact on an equal footing with social peers. In order to achieve participatory parity in a higher education context, social arrangements would have to be put in place which would make it possible for individuals to interact on a par with each other. All three of these dimensions are seen as being both analytically separate and entangled or intertwined but not reducible to the other. As Fraser $(2008,282)$ aptly puts it 'No redistribution or recognition without representation.' Thus, all social arrangements which are conducive to all three dimensions would have to be in place for social justice to be possible.

Each of the three dimensions of social justice can be viewed either from an affirmative or transformative perspective according to Fraser. From an affirmative perspective, social justice can be redressed by attending to the inequitable outcomes of social arrangements in ways which make ameliorative changes. Transformative approaches to social justice, on the other hand, address the root causes of the three dimensions through restructuring the generative framework which has given rise to impairment of participatory parity.

Considering socially just pedagogy from each of these dimensions: in higher education people can be prevented from participating as equals. Examples of the economic dimension include lack of access to material resources such as food, transport, housing, electricity, health care, social literacies, and funding, poorly paid or exploitative work such as continued casualisation that is now prevalent in higher education. Of concern for socially just pedagogy is how higher education students are charged differential fees which prevent those who do not have resources from access to higher education. Working class and poor students usually have to work to support themselves and family members, and they have less leisure time and less time for study than their middle class counterparts. Access to the Internet and Wi-Fi and ability to engage with digital literacies is important for participatory parity in higher education, both for students and for higher educators themselves. Affirmative approaches to dealing with these would be redistributing resources, by for example, providing national funding for study purposes without addressing inequities in the system itself. Social justice pedagogy would concentrate on transformative approaches which would examine how to change who gets to do what, (how responsibilities such as teaching and research are set and how research and teaching are valued (Bozalek and Carolissen 2012)).

In terms of the second dimension, of recognition and misrecognition, this relates to the cultural dimension. What is important for socially just pedagogy is how perceived attributes of people or practices are either valued (recognised) or devalued (misrecognised). This will impact on ways in which students and academics are able to participate in the pedagogical process. Fraser $(2008,2009)$ makes it clear that she is interested in institutionalised rather than psychological processes of valuing or devaluing - mis/recognition and status in/equalities. These forms of status inequality include: degrading students' prior 
knowledges, colonisation of settler groups where the values and attributes of certain other groups are backgrounded and rendered invisible in the curriculum. Part of the work of social justice pedagogy would be to alert people to these structural inequalities in the status order. In order to do this, it would be important to examine what knowledges are accorded less respect and esteem than others and who is valued or devalued in terms of cultural categories such as race, gender, sexuality, ability or nationality. Examples of institutional practices which would affect misrecognition would be institutional policies and practices which assume a normative social actor, such as white, male, middle class, heterosexual and where the attributes of other groups are implicitly regarded as deficient or inferior. Social justice pedagogies would consider ways of addressing these impediments to equal participation. Affirmative approaches would involve revaluing devalued categories such as indigenous knowledges or devalued social categories such as race, ability or class this may, however, reify groups of people along a single axis, such as women or blacks, thus reducing the lived complexity of situations. A more transformative social justice pedagogy would alert students to the possibility of destabilising institutionalised cultural patterns through deconstructing binary categories.

The third political dimension which has more recently been added by Fraser $(2008,2009)$ to the other two dimensions to accommodate transnational flows and practices, focuses on who belongs, and is included and who is excluded from higher education pedagogies. Fraser distinguishes between two forms of misrepresentation - the ordinary political one which has the national territorial state as its frame, where particular groups of people on the basis of social markers such as gender, race and ability are prevented from participation in their national political processes. The second form of misrepresentation is more serious, and concerns how political boundaries are set and who can be a member or not. In this way, people can be excluded from participating at all, and those who are poor or devalued have no way of challenging their situations - this she refers to as misframing. Misframing is the most serious form of injustice as it can be regarded as a political death. Misframing in higher education occurs because of a focus on individual institutions rather than the system as a whole thus depoliticising and misframing the gross inequalities in the education system as a whole, and placing the responsibility on the individual institution as such to 'pull themselves up by their own bootstraps' (see Bozalek and Boughey 2012, for a fuller discussion of this). With affirmative approaches, individual institutions and nation states would be accepted as the spaces of higher education that socially just and social justice pedagogies should concentrate on. From a transformative perspective, structural injustices pertaining to international or global issues such as the digital divide and differential access to knowledge production and consumption, all impact groups of people across national territories and individual higher educational or disciplinary contexts. Fraser's 'all affected' principle addresses how these common issues affect the life chances and ability to participate as equals of those affected by these across geopolitical contexts. In this case, the most effective way of addressing these issues would be through international socially just pedagogy, which provide students and academics with various fora to develop a more collective voice to express their concerns. 


\section{Supporting the growth of academics as scholars of teaching and learning}

We have chosen to illustrate this section of our argument with reference to three change initiatives that we have been involved in, in order to highlight the relationship between SoTL imbued with a social justice perspective and professional learning, because this is the domain of SoTL in relation to social justice that has been the most neglected. Our work to support the growth in SoTL amongst academics has been premised upon the notion that maldistribution, misrecognition and misframing affects academics in a like manner that it affects students. One could argue that this is less the case for academics, because to become an academic implies a greater level of social mobility, enculturation and access to dominant knowledges than would be the case for students. However in the previous section, we have argued that lack of participatory parity persists at this level, between institutions and within institutions. Furthermore, attention to the growth of academics as scholars of teaching and learning is extremely important in terms of sustainability, as academics would teach students in a socially just manner for many years, and would also be role models to students role models in terms of how they behave, teach, relate and the way they conduct their research with students.

\section{Three research-based interventions}

The observations we make in this section derive from research-based interventions where we have both collaborated, mostly in teams with others. The first is a short course for academics, called Citizenship, Social Inclusion and Difference (CSID) which was designed to give academics the opportunity to engage with techniques they could use with their students, in order to explore matters of difference in the classroom. Our teaching and research approach was based on a conceptual framework informed by the notion of a 'pedagogy of discomfort' (Boler and Zembylas 2003). We led this as part of a team of five educators. The course followed on from an action research intervention that was conducted three times with students across barriers of discipline, institution, race and class (see Leibowitz et al. 2012, for a full account of the student-oriented intervention) and we used many of the same educational techniques and principles in work with students and academics. The data we draw upon stem from the responses to participant feedback questionnaires to participant feedback questionnaires, reflective essays which were a requirement for completing the course, one published paper (Clowes 2013) and one conference paper authored by the academics, about their experiences of participating in the course. A total of 28 academics participated over the three years. All the data were analysed in order to ascertain how academics responded to this approach in comparison to students. For this article we provide quotes from the one published article and one reflective essay, by one white female and one black female, as these represent the depth and complexity of many of the reactions to the course.

The second intervention is an inter-institutional course designed and facilitated by colleagues from four universities in the Western Cape region and supported by the Cape Higher Education Consortium (CHEC), a body which aims to foster inter-institutional academic programme collaboration between these four institutions. The short course was entitled Research on Teaching and Learning: Preparing for your proposal (RTL) and was intended to build 
on academics' abilities to conduct educational research in their own contexts. To facilitate this, we familiarised academics with various educational research techniques, culminating in the participants' writing of an educational research proposal. Key sources of data for this project were the drawings by each of the 28 participants in which they documented their experiences and aspirations with regard to the SOTL; transcriptions of audio-taped focus group discussions of all participants in which they discussed their drawings with each other; and feedback from all participants about the short course. Project team members conducted an analysis of all the data according to the topics of researcher identity, emotions and the use of drawings. Presentations by two project team members and five course participants were made at a panel at a local teaching and learning conference (CHEC 2013). This was an attempt to draw the 'students' into the research production process as part of their experience of being on the course.

The third intervention is a collaborative research project undertaken by 18 South African academic developers at eight institutions on the subject of professional development. The six-year-long project is entitled Structure, Culture and Agency $(\mathrm{S}, \mathrm{C}+\mathrm{A})$. The primary focus of this research project was academics' uptake of professional development opportunities at 8 South African universities, but a secondary focus was the collaborative research process for the 18 participants. The data we use in this case were collected for two papers, Leibowitz, Ndebele, and Winberg (2014) and another in process, co-drafted by 14 of the researchers. The research design in this case was a form of group reflection. At the end of the first year of the collaboration all researchers submitted an unstructured reflective text. This was analysed by three of the team members for the above publication, with a focus on researcher identity. At the end of the third year, a second round of reflective texts was submitted in response to four questions. This has been analysed by 14 of the team members, using the constructs of reflexivity - how individuals and groups mediate the systemic conditions (Archer 2007) and relational reflexivity - how individuals consciously generate group agency (Donati 2010). Evidently, each intervention had its own research design and conceptual framework. For this article, we focus on the findings which pertain directly to the SOTL and its linkages to participatory parity.

\section{Outcomes and challenges}

In order to reflect on the implications for a socially just approach to support the SoTL, we provide examples of positive outcomes as well as challenges experienced by academics who participate in opportunities to grow as scholars of teaching and learning. Some of the challenges and outcomes are influenced by issues of maldistribution, malrecognition and misframing in the strong sense of inequality pertaining to class, race or gender. Some pertain to more subtle elements, for example, to the unequal status of teaching versus research, and some due to even less overtly political phenomena, for example, due to the challenges of crossing theoretical or disciplinary paradigms.

Examples from the data of the dimension of recognition and misrecognition in the experience of academics learning to research teaching and learning abound, even though these are not always explicitly tied to issues of social status. On the RTL short course 
lecturers described themselves as 'inadequate' because of their lack of experience with research in general, with one describing her proposal apologetically as 'lumpy' (female black academic from an $\mathrm{HDI}^{2}$ ). On the $\mathrm{S}, \mathrm{C}+\mathrm{A}$ project, even very seasoned researchers who had to work within a new theoretical domain felt inadequate. One of the participants in this collaborative research project even used the term 'at home', a term that has gained so much currency in the South African literature on transformation and inclusion in order to express feeling included:

I really enjoyed engaging with the group and drawing on their experience and knowledge. I felt very at home with the Project members. (Female white researcher from an HAI on S, C + A research project)

Vice (2015, 52) notes the interrelationship between feeling 'at home' and feeling productive and engaged, where she describes as feeling 'at home' as: 'we are in the "appropriate sphere of operation" of our agency'. Vice admits that the notion of feeling 'at home' is complex, as there are elements of feeling 'at home' that may be counterproductive. It is often maintained that there is a positive relationship between learning and discomfort. Nonetheless a certain degree of feeling at home is required, for an academic to flourish. In some instances feeling out of one's comfort zone and unable to participate is attributable to a sense of being a novice within a group:

... my own lack of knowledge about research and its processes caused me to feel unsure and sometimes even feeling totally stupid or ignorant which then kept me from participating or saying something. (Female white $\mathrm{PhD}$ student at $\mathrm{HAI}$ on $\mathrm{S}, \mathrm{C}+\mathrm{A}$ research project)

It is worth pointing out that both these statements were uttered by staff working in the field of academic professional development, who are not considered in their institutions to have academic status. This may have a constraining effect on their ability to work successfully with academics (Healey and Jenkins 2003). Maldistribution, misrecognition and misframing constitute social justice-related challenges for staff working in other support services too; for example, the library, as one of the participants in the RTL short course depicted in her drawing.

This is me climbing over a chain nail fence - you can see through it from libraryland ... you can see it through, but there is a distinct barrier from the faculty neighbourhood. ... (Female white participant from HDI on RTL short course)

Redistribution as a dimension of social justice can be considered in relation to cultural and educational capital, as well as material goods. The sharing of research know-how and resources was appreciated by more than one educational developer in the $\mathrm{S}, \mathrm{C}+\mathrm{A}$ collaborative research project: 
I think this, for me, has been one of the most astonishing characteristics of this group of colleagues - their generosity of spirit and willingness to share resources, intellectual property, and give generously of their time. (female white researcher from HDI on S, C + A project) Through a collaborative process with two seasoned researchers resulting in a publication in a highly rated higher education journal my confidence in publishing was boosted. (Male black researcher from HDI on S, C + A project)

Amongst the resources to which academics have access is the valued knowledges or cultural resources. In the $\mathrm{S}, \mathrm{C}+\mathrm{A}$ collaborative project, the theory which was chosen to inform the conceptual framework of the project operated as a form of cultural capital, with some research participants having access to this, and others not:

I gathered from the earlier paper that some of the project members found the social realism/ critical realism theoretical framework which was used for the project difficult and challenging. I suppose I was lucky to have come into the project with some of that theory. (Female white researcher from HAI on S, C + A project)

This participant's observation regarding her theoretical knowledge is not a trivial point in relation to social justice, as cultural resources such as theories are circulated and shared in settings such as institutions or departments, and academics privileged to work in those settings - not unlike students privileged to study in particular institutional settings benefit from such circulations. Access to theory was not expressed overtly as a social justice issue for those academics who teach in fields other than education, who find the transition to educational research a significant barrier. One academic in the RTL short course described his research journey as a hurdle, as 'crossing mount paradigm' (male white academic from HAI). However, if social arrangements and opportunities to access educational theory is denied to such an academic, this could indeed be described as a matter of social (in)justice. And certainly within research collaborations, one should attend to this as a crucial aspect of participatory parity, and hence social justice.

In the $\mathrm{S}, \mathrm{C}+\mathrm{A}$ research project material aspects of distribution or maldistribution that might impact on academics' participation were found to be: geographical proximity to the lead institution or to other researchers, or funding available to researchers in their own institutions, the latter which is often tied directly to institutional privilege (Bozalek and Boughey 2012).

Hindrances to participatory parity may be created by institutional affiliation or professional identity. Data from the S, C + A research project include the comment from an academic developer from a HDI who implied, by way of contrast, how his own lack of participation in the research project within which he participated was reversed:

Coming from an academic institution where research and publishing by the academic developers has in the past not been emphasised, the need to reflect on, and share our practices through research and publications on our practices is made critical by my 
involvement in a study of national magnitude. (Male black researcher from HDI on S, C + A research project)

Thus far the experiences of academics who have been supported in one way or another to grapple with RTL have been discussed in relation to the tripartite account of participatory parity. However, the account of social justice pedagogy provided in the early section of this paper referred to the need to include elements of destabilisation and the creation of discomfort (Boler and Zembylas 2003). These more discomforting aspects of pedagogy were reported as extremely productive, though not always, of course, easy. One participant in the CSID short course found the destabilising process significant for her personal development:

If it had not been for my involvement in this project, my life would probably have continued on a path of constant uncertainty and feelings of inadequacy - not so much because of others imposing these ideas on me, but because of me imposing it on myself (internalised oppression). I am grateful for having had the opportunity to be challenged in such a personal way, discomforting as it had been. (Female black academic from HAI on CSID short course)

This statement demonstrates clearly how the personal and professional lives and identities of academics are often highly interwoven (Bosetti 2015; Vice 2015). There were participants on the CSID short course who could see the linkages between the course, their own practice and their teaching, as this participant recorded in the final course evaluation: '[I learnt about] my part in perpetuating inequality and that I can change this through changing my teaching and learning.'

Opportunities for destabilisation, as productive as these may be, also contain inherent difficulties, as Clowes (2013), a female white academic at an HDI argues in her reflection as a participating academic on the CSID course. Clowes found the very process difficult, as the language used to discuss difference itself employs the same prioritisation of kinds of difference that are pervasive in post-apartheid society. In the article which she wrote about her experiences of participating in the course she contends that the participants in her cohort emphasised race over other aspects of difference such as gender, and that the facilitators endorsed this. Her struggle to convey her misgivings within the group were aggravated by her sense of risk that her dissension would be seen as lack of sensitivity to previously and presently oppressed black people. She concludes: 'South African educators need to find ways of talking about a shared future without reinscribing the same 'habits of practice' that constitute the very hegemonic discourses of inequality that require critique' (Clowes 2013, 717). Clowes' engagement with, but critique of, the methodology in the course suggests that there is much room for research into teaching and learning about social justice and in particular, but not solely, where educators are the target group.

\section{Conclusion}

In this article, we have attempted to flesh out implications of a social justice informed approach towards the SoTL for the support of academics to engage in the SoTL. These are 
for institutional arrangements which attend to the distribution of material as well as cultural resources amongst academics, and which attend to participatory process and a sense of inclusion and respect within research processes. Collaboration across institutional, disciplinary, national boundaries are necessary, provided that attention is paid to the opportunities for participatory parity, and where relevant, to opportunities for destabilisation and discomfort. Our examples are drawn from work in South Africa, but we contend that the SoTL and social justice for learners, educators and educational developers is an international issue.

We have found the tripartite approach to participatory parity as described by Fraser (2008, 2009) to be useful, in order to frame the discussion. Questions of participatory parity pervade all aspects of university life. We have attempted to illustrate how the social arrangements which are implicit in institutional, professional or disciplinary affiliation might serve to enable or constrain one's participation in research activities. We have not gone the next step, of demonstrating the benefit of engaging in social justice matters with academics, on the learning conditions for students - we recommend this as an important arena of study on the SoTL.

Regarding issues of social justice, we have tried to suggest the need for clear linkages between teaching and learning and research and suggest that processes and attributes based on one set of social justice principles should inform all of these relationships. If students are expected to collaborate and share, can their teachers do that? And do the teachers lead by example? If the students are expected to engage in troubling dialogues, do their teachers do that? Have the lecturers examined their long-held assumptions and deeply ingrained prejudices? If it is required that the curriculum makes place for scaffolding and enabling students to access the secrets of the disciplinary discourses of the academy, is provision made for academics to access learning theory and knowledge about research methods? To emphasise the interwovenness of all aspects of teaching and learning and the SoTL, we return to the words of Boyer, cited in the introduction to this article: 'good teaching means that faculty, as scholars, are also learners' (1990, 24).

This article is an attempt to respond to the dearth of articles written from a social justice perspective in the burgeoning field of SoTL, through its specific focus on the work of Nancy Fraser and participatory parity. It shows an attempt to go beyond the confines of educational theorising and to draw from the wisdom of other branches of knowledge such as philosophy and political science, to conceptualise what socially just pedagogies might involve. We would encourage further consideration of other approaches to social justice and socially just pedagogies in SoTL.

\section{Notes}

1. For the rest of this article, we use the term 'socially just pedagogy' as a shorthand, to refer to pedagogy for social justice as well. 
2. HDIs and HAIs are South African terms used to denote universities that were mainly for black students and under-resourced, or mainly for white students and well resourced, during the apartheid era.

\section{Disclosure statement}

No potential conflict of interest was reported by the authors.

\section{Funding}

This research was funded by the National Research Foundation, Grant No: 90384. 


\section{References}

Aljazeera. 2015. www.aljzeera.com/indepth/inpictures/2015/05/xenophobia-south-africa15050

Apple, M. 2013. Can Education Change Society? London: Routledge.

Apple, M., W. Au, and L. Gandin. 2009. "Mapping Critical Education." In The Routledge International Handbook of Critical Education, edited by M. Apple, W. Au and L. A. Gandin, 3-19. New York: Routledge.

Archer, M. 2007. Making Our Way Through the World: Human Reflexivity and Social Mobility. Cambridge: Cambridge University Press.

Badat, S. 2009. "Theorising Institutional Change: Post 1994 South African Higher Education." Studies in Higher Education 34 (4): 455-467.

Boler, M., and M. Zembylas. 2003. "Discomforting Truths: The Emotional Terrain of Understanding Difference.” In Pedagogies of Difference: Rethinking Education for Social Change, edited by P. Trifonas, 110-136. Falmer: Routledge.

Bosetti, L. 2015. "Academic Identity within Contested Spaces of a University within Transition." In Contested Sites in Education: The Quest for the Public Intellectual Identity and Service, edited by K. Ragoonaden, 107-112. New York: Peter Lang.

Boyer, E. 1990. Scholarship Reconsidered: Priorities of the Professoriate. Princeton, NJ: The Carnegie Foundation for the Advancement of Teaching.

Bozalek, V., and C. Boughey. 2012. "(Mis)Framing Higher Education in South Africa." Social Policy \& Administration 46 (6): 688-703.

Bozalek, V., and R. Carolissen. 2012. "The Potential of Critical Feminist Citizenship Frameworks for Citizenship and Social Justice in Higher Education." Perspectives in Education 30 (4): 9-18.

Brew, A. 2007. "Approaches to the Scholarship of Teaching and Learning." In Transforming a University: The Scholarship of Teaching and Learning in Practice, edited by A. Brew and J. Sachs, 1-10. Sydney: Sydney University Press.

Brew, A., and E. Jewell 2012. "Enhancing Quality Learning Through Experiences of Researchbased Learning: Implications for Academic Development.” International Journal for Academic Development 17(1):47-58.

CHEC (Cape Higher Education Consortium). 2013. "Aspirations and Experiences of Emerging Scholars of Teaching and Learning in Higher Education.” Annual Higher Education Learning and Teaching Association of Southern Africa (HELTASA) Conference, Pretoria, November 22-24.

Clowes, L. 2013. "Teacher as Learner: A Personal Reflection on a Short Course for South African University Educators." Teaching in Higher Education 18 (7): 709-720.

Cooper, D. 2015. "Social Justice and South African University Student Enrolment Data by 'Race', 1998-2012: From 'Skewed Revolution' to 'Stalled Revolution.'” Higher Education Quarterly 69 (3): 237-262.

Costandius, E. 2012. "Teaching Citizenship in Visual Communication Design: Reflections of an Afrikaner." In Higher Education for the Public Good: Views from the South, edited by B. Leibowitz, 155-162. Stellenbosch: SunMedia/Trentham Books. 
Department of Education. 2008. "Report of the Ministerial Committee on Transformation and Social Cohesion and the Elimination of Discrimination in Public Higher Education Institutions." Government Printers, Pretoria, November 30.

Donati, P. 2010. "Reflexivity After Modernity: From the Viewpoint of Relational Sociology." In Conversations about Reflexivity, edited by M. Archer, 144-164. Abingdon: Routledge.

Fraser, N. 2008. "Reframing Justice in a Globalizing World." In Adding Insult to Injury: Nancy Fraser Debates her Critics, edited by K. Olson, 273-291. London: Verso.

Fraser, N. 2009. Scales of Justice: Reimagining Political Space in a Globalizing World. New York: Columbia University Press.

Gale, R. 2009. “Asking Questions That Matter ... Asking Questions of Value.” International Journal for the Scholarship of Teaching and Learning 3 (2). http://digitalcommons.georgiasouthern.edu/ij-sotl/vol3/iss2/3

Gilpin, L., and D. Liston. 2009. "Transformative Education in the Scholarship of Teaching and Learning: An Analysis of SoTL Literature." 3 (2). http://digitalcommons.georgiasouthern.edu/ij-sotl/vol3/iss2/11

Griffiths, R. 2004. "Knowledge Production and the Research - Teaching Nexus: The Case of the Built Environment Disciplines." Studies in Higher Education 29 (6): 709-726.

Healey, M., and A. Jenkins. 2003. "Discipline-based Educational Development." In The Scholarship of Academic Development, edited by H. Eggins and R. MacDdonald, 47-57. Buckingham: SRHE and OUP.

Human Rights Watch. 2008. https://www.hrw.org/news/2008/05/22/south-africa-punishattackers- xenophobic-violence

Hutchings, P., ed. 2000. Opening Lines: Approaches to the Scholarship of Teaching and Learning. Princeton: Carnegie Foundation for the Advancement of Teaching and Learning.

Hutchings, P., M. Huber, and T. Ciccone. 2011. Scholarship of Teaching and Learning Reconsidered: Institutional Interaction and Impact. San Francisco, CA: Carnegie Foundation for the Advancement of Teaching. Jossey Bass.

Jansen, J. 2009. Knowledge in the Blood; Confronting Race and the Apartheid Past. Cape Town: UCT Press.

Kreber, C. 2013a. Authenticity In and Through Teaching in Higher Education. Abingdon: Routledge. Kreber, C. 2013b. "Empowering the Scholarship of Teaching: An Arendtian and Critical Perspective." Studies in Higher Education 38 (6): 857-869.

Leibowitz, B., and V. Bozalek. 2014. "Access to Higher Education in South Africa: A Social Realist Account." Widening Participation and Lifelong Learning 16 (1): 91-109.

Leibowitz, B., V. Bozalek, R. Carolissen, L. Nicholls, P. Rohleder, and L. Swartz. 2010. "Bringing the Social into Pedagogy; Unsafe Learning in an Uncertain World." Teaching in Higher Education 15 (2): 123-133.

Leibowitz, B., C. Ndebele, and C. Winberg. 2014. "The Role of Academic Identity in Collaborative Research." Studies in Higher Education 39 (7): 1256-1269.

Leibowitz, B., L. Swartz, V. Bozalek, R. Carolissen, L. Nichols, and P. Rohleder, eds. 2012. Community, Self and Identity: Educating South African University Students for Citizenship. Cape Town: HSRC Press.

Mabokela, R. 2000. "'We Cannot Find Qualified Blacks': Faculty Diversification Programs at South African Universities." Comparative Education 36 (1): 95-112. 
Moje, E. 2007. "Chapter 1: Developing Socially Just Subject-Matter Instruction: A Review of the Literature on Disciplinary Literacy Teaching." Review of Research in Education 31: 144 .

Ragoonaden, K. 2015. "Setting the Path Towards Emancipatory Practices.” In Contested Sites in Education: The Quest for the Public Intellectual, Identity and Service, edited by K. Ragoonaden, 9-20. New York: Peter Lang.

Soudien, C. 2008. "The Intersection of Race and Class in the South African University: Student Experiences." South African Journal of Higher Education 22 (3): 662-678.

Tabensky, P., and S. Matthews. 2015. Being at Home: Race, Institutional Culture and Transformation at South African Higher Education Institutions. Pietermaritzburg: University of Kwa-Zulu Natal Press.

Vice, S. 2015. "Feeling at Home': The Idea of Institutional Culture and the Idea of a University." In Being at Home: Race, Institutional Culture and Transformation at South African Higher Education Institutions, edited by P. Tabensky and S. Matthews, 45-71. Pietermaritzburg: UKZN Press. 